|| ISSN(online): 2589-8698 || ISSN(print): 2589-868X || International Journal of Medical and Biomedical Studies

Available Online at www.ijmbs.info

PubMed (National Library of Medicine ID: 101738825)

Index Copernicus Value 2017: 40.03

Original Research Article

Volume 3, Issue 3; March: 2019; Page No.122-132

\title{
COMPARATIVE EVALUATION OF EFFICACY AND SAFETY OF ASPIRIN + CLOPIDOGREL WITH ASPIRIN+TICAGRELOR IN PATIENTS WITH CARDIOVASCULAR DISEASES. AN OBSERVATIONAL STUDY.
}

\author{
Dr. Pinki Saini ${ }^{1}$, Dr. Poonam Patel ${ }^{2}$, Dr. Murtuza Bhora ${ }^{3}$, Dr. S. Tripathi ${ }^{4} \&$ Dr. P. Nyati ${ }^{5}$ \\ PG Resident ${ }^{1}$, Associate Professor ${ }^{2}$, Assistant Professor ${ }^{3}$, Professor $^{4}$, Professor $\&$ Head $^{5}$ \\ Department of Pharmacology, Index Medical College, Indore
}

Article Info: Received 22 February 2019; Accepted 20 March. 2019

Cite this article as: Saini, Dr. P., Patel, Dr. P., Bhora, Dr. M., Tripathi, Dr. S., \& Nyati, Dr. P. (2019). COMPARATIVE EVALUATION OF EFFICACY AND SAFETY OF ASPIRIN + CLOPIDOGREL WITH ASPIRIN+TICAGRELOR IN PATIENTS WITH CARDIOVASCULAR DISEASES. AN OBSERVATIONAL STUDY. International Journal of Medical and Biomedical Studies, 3(3).

DOI: https://doi.org/10.32553/ijmbs.v3i3.157

Address for Correspondence: Dr. Poonam Patel, Associate Professor, Department of Pharmacology, Index Medical College, Indore

Conflict of interest: No conflict of interest.

\section{Abstract}

Background: Coronary artery disease (CAD) is one of the most common causes of mortality and morbidity in both developed and developing countries. It is a leading cause of death in India, and its contribution to mortality is rising. Platelets play an essential role in the pathogenesis of acute coronary syndromes (ACS). Therefore an important part of the treatment of ACS, and of primary and secondary preventive measures in coronary heart disease, consists of antiplatelet treatment. Dual antiplatelet therapy (DAPT) provides more intense platelet inhibition than single antiplatelet therapy resulting in incremental reductions in the risk of thrombotic events after percutaneous coronary intervention (PCl) or ACS, but it has been associated with an increased risk of major bleeding. It is interesting to consider that there is no Indian data on the efficacy of recently developed antiplatelet drugs other than in combination with aspirin, and that we remain unaware of the extent to which combinations with aspirin improve efficacy but increase risk.

Methodology: Study was prospective, observational clinical study carried out in the Department of Medicine, of Index Medical College Hospital \& Research Centre. A total of 80 patients with CAD were enrolled for the study and were equally divided in two groups each of 40 for evaluating efficacy and safety of dual antiplatelet therapy. Follow-up was done at 8 weeks, 16 weeks, and 24 weeks, patients were asked to provide information regarding their current medications, any morbidity and their complications [if any]. Demographic parameters were analyzed by descriptive statistics. Comparison between groups was done by Chi-square Test. Survival analysis was done by suitable statistical method.

Result: The median age was 55 years in group 1 and 57 years in group 2. Hypertension was most common associated disorders in group 1 [25 (62.55\%)] and group 2 [27 (67.5\%)], which was followed by diabetes and dyslipidemia. index events for present study enrolment was unstable angina, non-STsegment elevation MI, ST-segment elevation MI and others amongs the study groups. With 6 months of follow-up, the rate of the primary event like death from any cause was 7.5 percent in the clopidogrel 
plus aspirin group and 2.5 percent in the ticagrelor plus aspirin group. The primary safety end point (severe bleeding) was $2.5 \%$ in the clopidogrel plus group 1 and none in group 2.

Conclusion: the combination of clopidogrel plus aspirin was found to be non inferior to aspirin plus ticagrelor dual therapy in reducing the rate of myocardial infarction, stroke, or death from cardiovascular causes among patients with stable cardiovascular disease or multiple cardiovascular risk factors. The risk of moderate to severe bleeding was increased slightly in both the groups. Our findings do support the use of dual antiplatelet therapy across the broad population tested where single antiplatelet therapy are not giving maximum benefits

Keywords: Acute coronary syndrome (ACS), percutaneous coronary intervention ( $\mathrm{PCl})$, Coronary artery disease (CAD), Dual antiplatelet therapy (DAPT)

\section{Introduction:}

Cardiovascular diseases (CVDs) are a group of disorders of the heart and blood vessels and they include ${ }^{1}$ coronary heart disease, cerebrovascular disease, Peripheral arterial disease, Rheumatic heart disease, Congenital heart disease, Deep vein thrombosis and Pulmonary embolism. Cardiovascular diseases remain the most common causes of death, responsible for $35 \%$ of all deaths, almost 1 million deaths each year. Approximately one-fourth of these deaths are sudden. In addition, cardiovascular diseases are highly prevalent, diagnosed in 80 million adults, or $\sim 35 \%$ of the adult population ${ }^{2}$. Ischemic heart disease (IHD) and stroke constitute the majority of CVD mortality in India (83\%), with IHD being predominant $^{3}$. The ratio of IHD to stroke mortality in India is significantly higher than the global average, and is comparable to that of Western industrialized countries. Most cardiovascular diseases can be avoided or delayed by cut shorting the risk factors such as tobacco use, unhealthy diet and obesity, physical inactivity and harmful use of alcohol using population-wide strategies. People with cardiovascular disease or who are at high cardiovascular risk (due to the presence of one or more risk factors such as hypertension, diabetes, hyperlipidaemia or already established disease) need early detection and management using counselling and medicines, as appropriate ${ }^{4}$. Atherosclerosis is a chronic inflammatory process that is known to be the underlying cause of coronary artery disease $(C A D)^{5}$. In addition to being the first step of primary hemostasis, platelets play a pivotal role in the thrombotic process that follows rupture, fissure, or erosion of an atherosclerotic plaque ${ }^{6}$. Because atherothrombotic events are essentially plateletdriven processes, this underscores the importance of antiplatelet agents, which represent the cornerstone of treatment, particularly in the settings of patients with acute coronary syndromes (ACS) and undergoing percutaneous coronary intervention $(\mathrm{PCl})$. Platelets play an essential role in the pathogenesis of acute coronary syndromes $(\mathrm{ACS})^{7}$. Therefore an important part of the treatment of ACS, and of primary and secondary preventive measures in coronary heart disease, consists of antiplatelet treatment. Over the years antiplatelet treatment has evolved and currently several types of antiplatelet drugs are available, each with their specific pharmacological target and with their specific clinical indications. Dual antiplatelet therapy (DAPT) comprising of aspirin and a P2Y12 inhibitor is one of the most commonly prescribed therapies in cardiovascular medicine. Dual antiplatelet therapy (DAPT) provides more intense platelet inhibition than single antiplatelet therapy resulting in incremental reductions in the risk of thrombotic events after percutaneous coronary intervention (PCI) or ACS, but it has been associated with an increased risk of major bleeding. It is interesting to consider that there is no Indian data on the efficacy of recently developed antiplatelet drugs other than in combination with aspirin, and that we remain unaware of the extent to which combinations with aspirin improve efficacy but increase risk. 
Therefore this observational study was planned with aim to evaluate the safety and efficacy of antiplatelet drugs in combination Group 1 [patients under aspirin plus clopidogrel], group 2 [aspirin plus ticagrelor] in patients with cardiovascular disorders in Indian populations.

Our Primary Objectives were: 1 . To evaluate the safety and efficacy of antiplatelet drugs in combination Group 1[aspirin + clopidogrel], and group 2 [aspirin + ticagrelor] in patients with CAD.

2. To evaluate any cardiovascular/ atherothrombotic events on patients with antiplatelet therapy.

3. To study the primary bleeding endpoint, is the time to first occurrence of clinically relevant bleeding, defined as Bleeding Academic Research Consortium (BARC) Types 2, 3 or 5 bleeding.

4. To find out percentage of complications [side effect like gastrointestinal and/or nervous and/or allergic manifestations] in patients on antiplatelet drugs regimen attending Medicine OPD

\section{Methods}

Study was prospective, observational clinical study carried out in the Department of Medicine, of Index Medical College Hospital \& Research Centre. Permission from the Institutional Ethics Committee was obtained before starting research work. All decisions relating to management of the patient including drugs and investigations was taken by the treating physician only. Investigator did not interfere in the management of patient and only observed the proceedings. Subjects and their accompanying family members were interviewed by pre-structured questionnaire, and past and present prescriptions and case notes, wherever available, were obtained and reviewed. Data regarding anti-platelet mono-therapy and combination therapy were recorded. Other coadministered drugs was recorded. A total of 80 patients with CAD were enrolled for the study with 40 subjects in each group, Group 1 [aspirin + clopidogrel] and group 2 [aspirin + ticagrelor].
Follow-up was done at 8 weeks, 16 weeks, and 24 weeks, patients were asked to provide information regarding their current medications, any morbidity and their complications [if any].

\section{Inclusion Criteria:}

1) Subjects who was suffering from cardiovascular disorders and prescribed antiplatelet drugs at Medicine O.P.D.

2) Adult patient's $\geq 18$ years of age of both the sex was included.

3) CAD patients with co-morbidities like diabetes mellitus, ischemic heart diseases, congestive heart failure and chronic renal diseases were also included in the study.

4) Those who understood the purpose of the study and were ready to provide information regarding their health status along with a signed informed consent document.

\section{Exclusion Criteria:}

1) Under 18 years of age

2) Contraindication to antiplatelet agents like aspirin, ticagrelor etc.

3) Planned surgery within 90 days

4) Planned coronary revascularization (surgical or percutaneous) within 90 days

5) Need for chronic oral anticoagulation

6) Dialysis-dependent renal failure

7) Active bleeding or extreme-risk for major bleeding (e.g. active peptic ulcer disease, gastrointestinal pathology with a raised risk for bleeding, malignancies with a raised risk for bleeding)

8) Salvage PCI or STEMI presentation

9) Liver cirrhosis

10) Unable or unwilling to provide informed consent

11) Women of child bearing potential (as determined by hospital standard of care)

12) Fibrinolytic therapy within 24 hours of index $\mathrm{PCl}$ 
13) Patients with thrombocytopenia or any other hematological abnormality. Any conditions resulting in severe learning disability (e.g. brain injury).

14) Those unable to comprehend for other reasons will be excluded from the study.

\section{Statistical Analysis Plan:}

1) Demographic parameters was analyzed by descriptive statistics

2) Comparison between groups was done by $\mathrm{Chi}-$ square Test

3) Survival analysis by suitable statistical method

\section{Results}

A total of 80 patients with CAD were enrolled for the study and equally divided in two groups to see efficacy and safety of dual antiplatelet therapy. The median age was 55 years in group 1 and 57 years in group 2; 22.5 percent and $17.5 \%$ of the patients were women in group 1 and group 2 respectively. Majority of the participants were male in both the groups [group 1, 77.5\% \& group 2, 82.5\%] table1. Hypertension was most common associated disorders in group 1 [25 (62.55\%)] fig.1 and group 2 [27 (67.5\%)] fig.2, which was followed by diabetes and dyslipidemia. Good numbers of study participants were chronic smokers. Percentage of index events for present study enrolment was unstable angina (27.5\%/37.5\%), non-ST-segment elevation $\mathrm{MI}(30 \% / 27.5 \%)$, ST-segment elevation $\mathrm{MI}(40 \% / 35 \%)$ and others (2.5\%/0) fig.3 among the study groups. Three quarters took a statin, and more than half took a beta-blocker, proton pump inhibitors. Nearly one thirds took a diuretics, ACE inhibitor or angiotensin II-receptor blocking agents.(fig.4)

Table 1: Baseline Characteristics of study participants

\begin{tabular}{|l|l|l|}
\hline Characteristic & Clopidogrel plus Aspirin (N=40) [Group 1] & Ticagrelor plus Aspirin (N = 40) [Group 2] \\
\hline $\begin{array}{l}\text { Demographic } \\
\text { characteristics }\end{array}$ & & \\
\hline $\begin{array}{l}\text { Age - yr } \\
\text { Median }\end{array}$ & $51.01 \pm 11.62$ & $52.08 \pm 10.98$ \\
Range & $35-83$ & 57 \\
\hline $\begin{array}{l}\text { Age groups } \\
<40 \text { yrs }\end{array}$ & $6(15 \%)$ & $40-79$ \\
$40-60$ yrs & $23(57.5 \%)$ & $4(10 \%)$ \\
$>60 y r s$ & $11(44 \%)$ & $21(52.5 \%)$ \\
\hline Sex $[\mathrm{M} / \mathrm{F}]$ & $31[77.5 \%] / 9[22.5 \%] ; 3.44: 1$ & $15(37.5 \%)$ \\
\hline
\end{tabular}

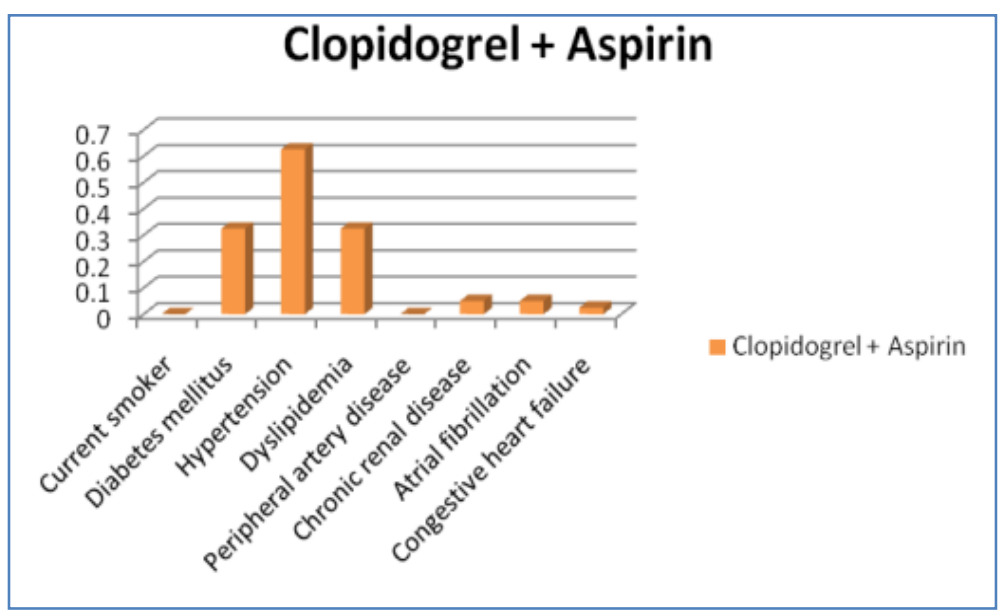

Figure 1: Distribution of cardiovascular risk factors among group1 patients 


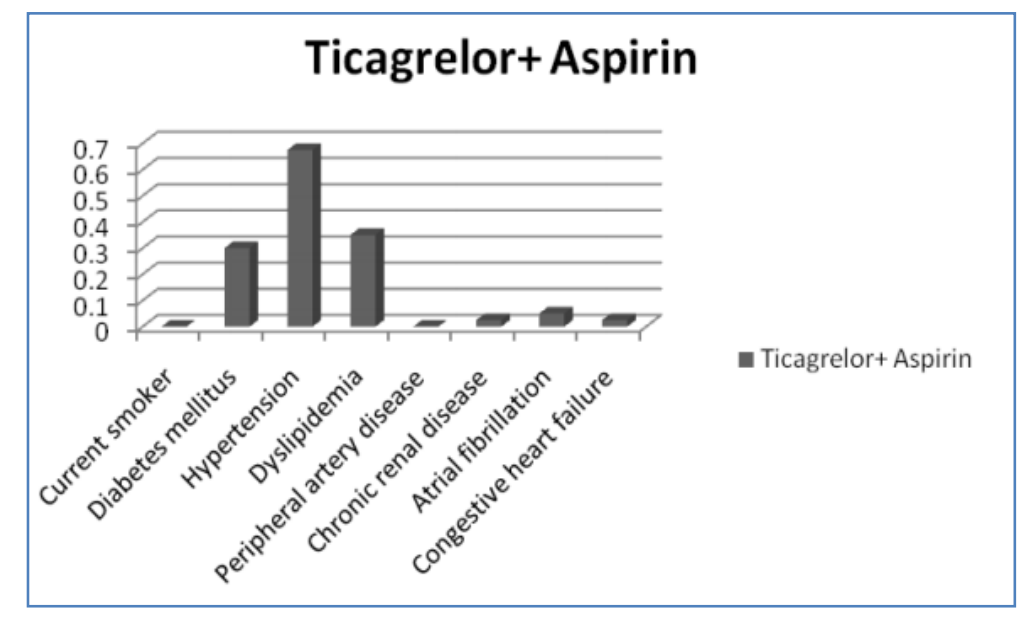

Figure 2: Distribution of cardiovascular risk factors among group2 patients

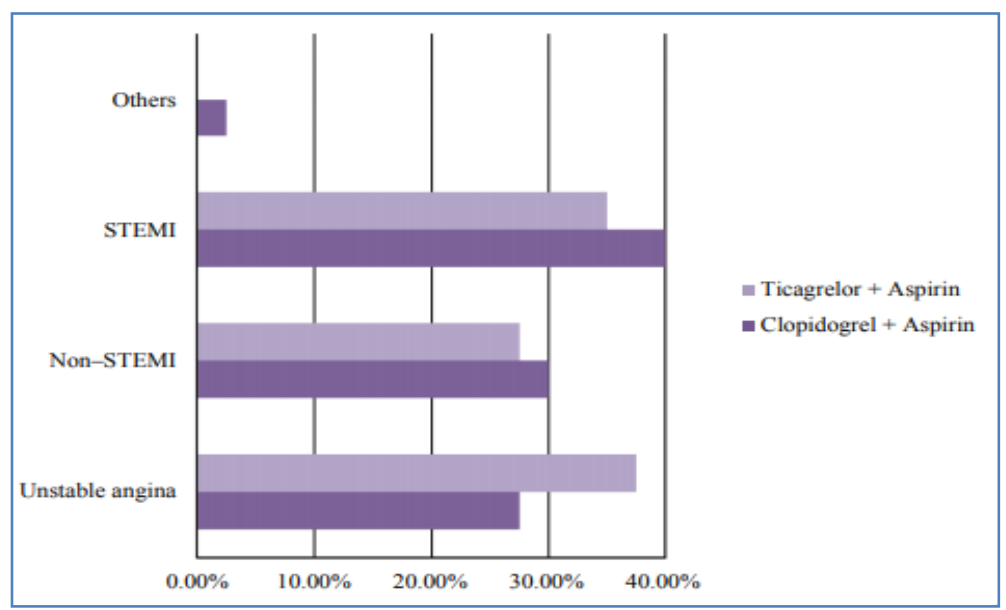

Figure 3: Distribution of present cardiovascular index events among study particpiants

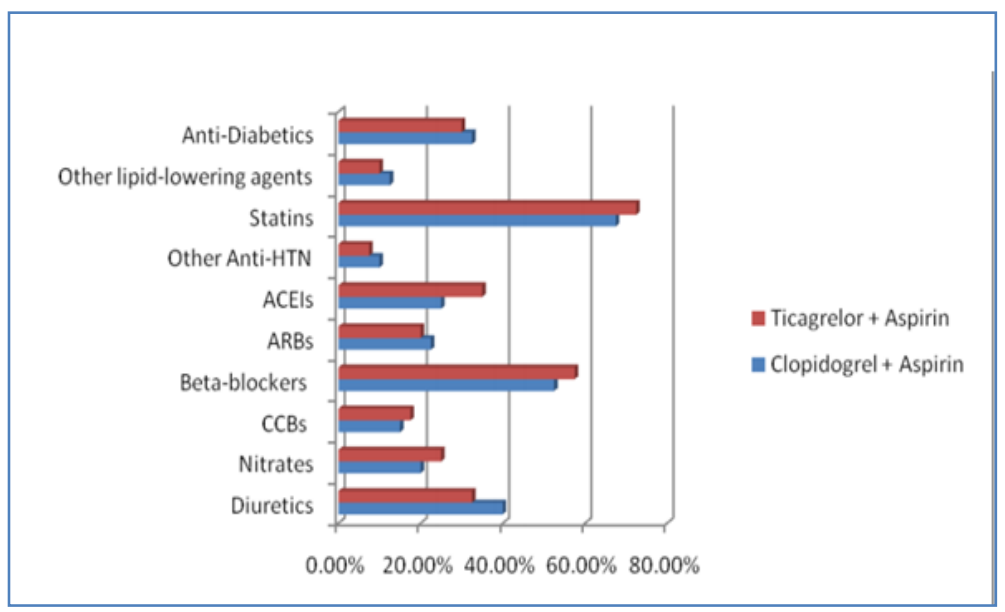

Figure 4: Percentage of concomitant medication intake by study participants

With 6 months of follow-up, the rate of the primary event like death from any cause was 7.5 percent in the clopidogrel plus aspirin group and 2.5 percent in the ticagrelor plus aspirin group (relative risk, 1.5; 95 percent confidence interval, 0.2647 to 8.5010; $\mathrm{P}=0.6469$ ). The rate of the principal secondary efficacy end point (the first occurrence of myocardial infarction, stroke, or 
hospitalization for unstable angina, transient ischemic attack, or a revascularization procedure) was 10 percent in the clopidogrel plus group, as compared with 7.5 percent in the ticagrelor plus group 2 (relative risk, 1.33; 95 percent confidence interval, 0.3186 to 5.5793; $\mathrm{P}$ $=0.6936)$. table 2

The rate of the primary safety end point (severe bleeding according to the GUSTO definition) was 2.5 percent in the clopidogrel plus group 1 and none in group 2. The rate of moderate bleeding was $5 \%$ percent in the ticagrelor group, as compared with zero percent in the clopidogrel plus aspirin group. The rate of intracranial hemorrhage was $5 \%$ and $2.5 \%$ in the two treatment groups respectively. About $12.5 \%$ and $10 \%$ of patients treated ticagrelor plus aspirin and clopidogrel plus aspirin developed dyspnea respectively. Dyspnea was usually mild (majority of the reported cases) to moderate in intensity which led to study drug discontinuation and often resolved during continued treatment. Only few cases serum uric acid levels increased approximately $0.75 \mathrm{mg} / \mathrm{dL}$ from baseline on group 1 and approximately $0.38 \mathrm{mg} / \mathrm{dL}$ on group 2. (Fig 6)

Table 2: Safety and efficacy outcomes among participants in two groups

\begin{tabular}{|c|c|c|c|c|}
\hline Outcome & $\begin{array}{l}\text { Clopidogrel } \\
\text { plus Aspirin } \\
(\mathrm{N}=40) \\
\text { [Group 1] }\end{array}$ & $\begin{array}{l}\text { Ticagrelor plus } \\
\text { Aspirin ( } \mathrm{N}= \\
40 \text { ) No. of } \\
\text { patients (\%) }\end{array}$ & $(95 \% \mathrm{Cl})$ & P Value \\
\hline $\begin{array}{l}\text { Primary end point } \\
\text {-Death from any cause }\end{array}$ & $3(7.5 \%)$ & $2(5 \%)$ & $\begin{array}{l}95 \% \mathrm{Cl}-10.0104 \text { to } \\
15.3827\end{array}$ & $\begin{array}{l}P= \\
0.6462\end{array}$ \\
\hline -Death from cardiovascular causes & $2(5 \%)$ & $2(5 \%)$ & $\begin{array}{l}95 \% \mathrm{Cl}-12.0594 \text { to } \\
12.0594\end{array}$ & $\begin{array}{l}P= \\
1.0000\end{array}$ \\
\hline -Myocardial infarction (nonfatal) & $3(7.5 \%)$ & $3(7.5 \%)$ & $\begin{array}{l}95 \% \mathrm{Cl}-13.3058 \text { to } \\
13.3058-\end{array}$ & $\begin{array}{l}P= \\
1.0000\end{array}$ \\
\hline -Stroke (fatal) & $1(2.5 \%)$ & 0 & & \\
\hline -Ischemic stroke (nonfatal) & 0 & 0 & & \\
\hline -Stroke (nonfatal) & $1(2.5 \%)$ & $1(2.5 \%)$ & $\begin{array}{l}95 \% \mathrm{Cl}-10.5833 \text { to } \\
10.5833\end{array}$ & $\begin{array}{l}P= \\
1.0000\end{array}$ \\
\hline $\begin{array}{l}\text { Secondary efficacy end point } \\
\text { Hospitalization for unstable angina, } \\
\text { transient ischemic attack, or } \\
\text { revascularization }\end{array}$ & $4(10 \%)$ & $3(7.5 \%)$ & $\begin{array}{l}95 \% \mathrm{Cl}-11.2616 \text { to } \\
16.4470\end{array}$ & $\begin{array}{l}\mathrm{P}= \\
0.6942\end{array}$ \\
\hline $\begin{array}{l}\text { Safety end points } \\
\text { Major bleeding } \\
\text {-Moderatebleeding } \\
\text { Minor bleeding }\end{array}$ & $\begin{array}{c}1(2.5 \%) \\
0 \\
5(12.5 \%)\end{array}$ & $\begin{array}{l}0 \\
2(5 \%) \\
3(7.5 \%)\end{array}$ & $\begin{array}{l}- \\
- \\
- \\
95 \% \mathrm{Cl}-9.2282 \text { to } \\
19.4728\end{array}$ & $\begin{array}{l}P_{0.4589}= \\
=\end{array}$ \\
\hline
\end{tabular}


Table 3: Types of Bleeding among study participants

\begin{tabular}{|l|l|l|l|}
\hline Bleeding Type & Mild & Moderate & Severe \\
\hline Conjunctival & 0 & 0 & 0 \\
\hline Epistaxis & $1(2.5 \%)$ & 0 & 0 \\
\hline Gastrointestinal & $4(10 \%)$ & $1(2.5 \%)$ & $1(2.5 \%)$ \\
\hline Gingival & 0 & 0 & 0 \\
\hline Hemoptysis & 0 & 0 & 0 \\
\hline Hematuria & 0 & 0 & 0 \\
\hline Intracranial & $2(5 \%)$ & $1(2.5 \%)$ & 0 \\
\hline Intraocular & 0 & 0 & 0 \\
\hline Puncture site & $1(2.5 \%)$ & 0 & 0 \\
\hline Retroperitoneal & 0 & 0 & 0 \\
\hline Surgical & 0 & 0 & 0 \\
\hline Other & 0 & 0 & 0 \\
\hline
\end{tabular}

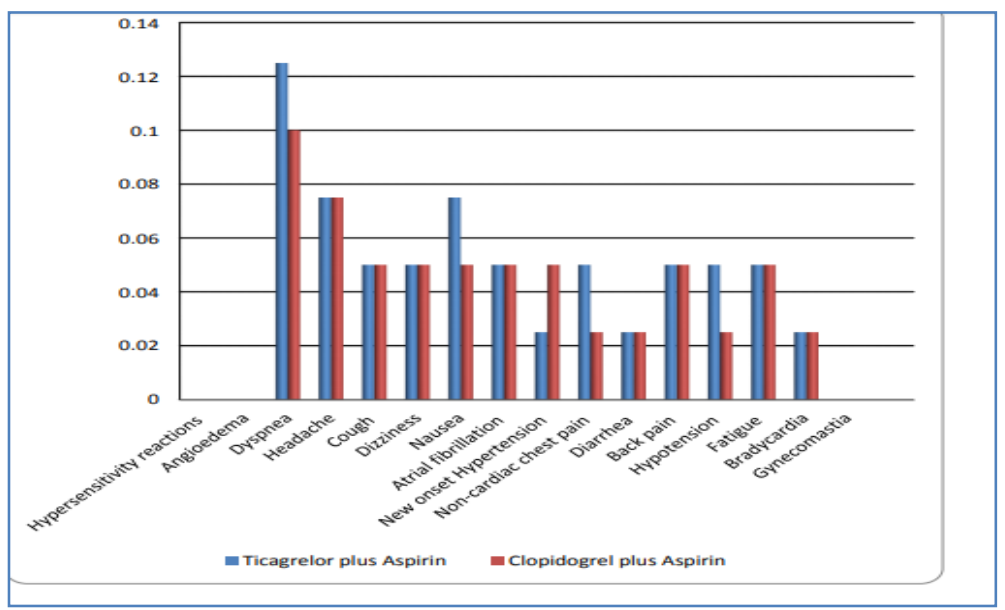

Figure 6: Percentage of patients reporting non-hemorrhagic adverse events in either group

\section{Discussion:}

Atherosclerotic vascular disease has a propensity to engender arterial thrombosis, a sequence that has been characterized as an atherothrombotic process $^{7,8}$.

Collectively, atherothrombotic disorders of the coronary, cerebrovascular, and peripheral arterial circulation are the leading cause of death and disability in the world ${ }^{9}$. Their prevalence is increasing, and better means of prevention are needed $^{10}$. Platelets have been shown to play a major role in the pathogenesis of atherothrombosis ${ }^{7,8}$. Low-dose aspirin has been shown to reduce ischemic outcomes in patients above a certain risk threshold ${ }^{11}$. However, aspirin alone in many instances is not sufficient to prevent ischemic events in patients at high risk. Furthermore, aspirin inhibits only the cyclooxygenase pathway, leaving the adenosine diphosphate P2Y12 receptor unaffected. Dual antiplatelet therapy with clopidogrel, a P2Y12receptor antagonist, plus aspirin has been shown to reduce ischemic events in patients with unstable angina, myocardial infarction without ST segment elevation, or myocardial infarction with ST-segment elevation, as well as those undergoing angioplasty and stenting ${ }^{12,13,14,15}$.

In our study the median age of the patient was 55 years in group 1 and 57 years in group 2; 22.5 percent and $17.5 \%$ of the patients were women 
in group 1 and group 2 respectively. Study by Kang $\mathrm{HJ}$ et al (2015) showed Asian patients were slightly but significantly younger and had lower body weight and body mass index than nonAsian patients ${ }^{16}$. Hypertension was most common associated disorders in group 1 [25 (62.55\%)] and group 2 [27 (67.5\%)], which was followed by diabetes and dyslipidemia. Good number of study participants was chronic smokers. There were cases of previous ischemic stroke, previous TIA, previous myocardial infarction, and prior percutaneous coronary intervention/ $\mathrm{PCl}$ in both the groups. Median baseline SBP blood pressure was noted 152 and $156 \mathrm{mg} \mathrm{Hg}$ in the study groups. Percentage of index events for present study enrolment was unstable angina $(27.5 \% / 37.5 \%)$, non-ST-segment elevation $\mathrm{MI}(30 \% / 27.5 \%)$, ST-segment elevation $\mathrm{MI}$ (40\%/ 35\%) and others (2.5\%/0) among the study groups.(Fig3). PLATO Trial revealed that cardiovascular risk factors like current smoking status and diabetes mellitus were more common in Asian patients; hypertension and dyslipidemia were more common in non-Asian patients. Asian patients less commonly reported a previous $\mathrm{MI}$ or coronary revascularization, but a history of nonhemorrhagic stroke was more common in Asian patients. At the time of randomization, the most common type of ACS event in Asian patients was ST-segment elevation $\mathrm{MI}$, whereas non-ST-segment elevation $\mathrm{MI}$ was more common in nonAsian patients ${ }^{16}$. Study by Zhao $Q$ et al (2018) identified in their study that the patients had mean age of $63.6 \pm 8.2$ years, were prevalent men $(81.8 \%)$, and traditional ischemic risk factors were well represented (diabetes mellitus $43.4 \%$, smoking $49.2 \%$, hypertension $73.8 \%$, hyperlipidaemia $72.2 \%$ ). Unstable angina was the most common clinical presentation $(62.8 \%)^{17}$.

Aspirin is an irreversible cyclooxigenase-1 inhibitor indicated to reduce the risk of recurrent vascular events in patients with a history of cardiovascular disease $^{18}$. In the present study almost all the patients (aside from those who died or dropped out) took aspirin and the either clopidogrel/ticagrelor drug in combination. Three quarters took a statin, and more than half took a beta-blocker, proton pump inhibitors. Nearly one thirds took a diuretics, ACE inhibitor or angiotensin II-receptor blocking agents [Fig 4]. PLATO Trial revealed that concomitant medication was also significantly different between the 2 groups. In Asian patients, a lower proportion was treated with aspirin, $\beta$-blocker, statin, and glycoprotein Ilb/IIla inhibitor at baseline. A higher proportion of Asian patients than non-Asian patients had a planned invasive strategy ${ }^{16}$.

The proportion of antiplatelet drug users at 6 months found in the present study was similar to that found in the EuroAspire III survey in the Netherlands ${ }^{19}$. Study had shown that the proportion of Ml patients who persistently used antiplatelet drugs was relatively high in the first year, it was not optimal. A discontinuation of antiplatelet drugs early after $\mathrm{CHD}$ and $\mathrm{PCl}$ might lead to a recurrent ACS event ${ }^{20,21}$. In the present study, the non persistent user proportion at 6 months was driven mostly by early discontinuation due to moderate to severe bleeding. But they restarted dual antiplatelet therapy once their complications were resolved within a gap of few weeks. Decision of restarting antiplatelet therapy purely decided by treating physician based on seriousness of adverse events and how first patients recovered the study by Yasmina A et al (2017) showed that in $30 \%$ of the patients who discontinued antiplatelet drugs within 6 months after the first $\mathrm{MI}$, a recurrent ACS occurred within 6 months after the discontinuation date ${ }^{21}$. Early antiplatelet discontinuation might be caused by drug intolerance, major bleeding, invasive procedures, co-medications and patient-related factors ${ }^{20,} 22$. The average adherence to any antiplatelet drug and aspirin was relatively high, while clopidogrel adherence was low ${ }^{22}$. A study by Tuppin et al., in France, showed an approximately similar proportion (81.7\%) of adherent users of antiplatelet drugs (aspirin and clopidogrel) ${ }^{23}$ to that in our study (78.9\%). Another study, in Italy, showed a lower proportion of adherent antiplatelet drug users $(58.7 \%)^{24}$. The population 
of $\mathrm{Ml}$ patients in our study were, on average, younger than that in the Italian study. Younger patients tend to be more adherent to treatment than older patients ${ }^{23}$, as also observed in the present study. However, even the older patients in the present study showed a high adherence to antiplatelet drugs.

With a median of 6 months of follow-up, the rate of the primary event like death from any cause was 7.5 percent in the clopidogrel plus aspirin group and 2.5 percent in the ticagrelor plus aspirin group (relative risk, 1.5; 95 percent confidence interval, 0.2647 to $8.5010 ; \mathrm{P}=$ 0.6469) [Table 2]. the rate of the principal secondary efficacy end point (the first occurrence of myocardial infarction, stroke, or hospitalization for unstable angina, transient ischemic attack, or a revascularization procedure) was 10 percent in the clopidogrel plus group, as compared with 7.5 percent in the ticagrelor plus group 2 (relative risk, 1.33; 95 percent confidence interval, 0.3186 to $5.5793 ; \mathrm{P}$ $=0.6936$ ).

The rate of the primary safety end point (severe bleeding according to the GUSTO definition) was 2.5 percent in the clopidogrel plus group 1 and none in group 2 . The rate of moderate bleeding was $5 \%$ percent in the ticagrelor group, as compared with zero percent in the clopidogrel plus aspirin group. The rate of intracranial hemorrhage was $5 \%$ and $2.5 \%$ in the two treatment groups respectively (table 3 ).

In this observational study of secondary prevention in patients with cardioembolic ischemic stroke and transient ischemic attack who underwent dual antithrombotic therapy after symptom onset and who did not receive thrombolytic therapy, events included in the primary end point - a composite of stroke, myocardial infarction, or death - were not less common among patients who received ticagrelor plus aspirin than among patients who received clopidogrel plus aspirin during the 180-days follow-up period. There was no evidence of a higher risk of major or intracranial hemorrhage with ticagrelor plus aspirin than clopidogrel with aspirin, but there were more instances of dyspnea and less minor bleeding in the ticagrelor group. In a large, international trial of secondary prevention by Johnston SC et al $(2016)^{25}$ the results were same. In the PLATO study, the primary efficacy end point and net clinical benefits favoured ticagrelor compared with clopidogre $^{26,27}$. In the present study, the net clinical benefits of ticagrelor group compared with clopidogrel were not different between patients, although there were differences in baseline characteristics and cardiovascular event rates between groups. Similarly, there was no significant heterogeneity in effects of ticagrelor plus aspirin group compared with clopidogrel plus aspirin on efficacy, bleeding, and other safety end points. The overall net clinical benefit of ticagrelor plus aspirin was primarily the result of reduced cardiovascular events, exceeding the observed increase of major bleeding in patients. In the PLATO (Platelet Inhibition and Patient Outcomes) trial, researchers looked at patients hospitalized for an ACS event who were about to receive medical or invasive management. They found that ticagrelor was associated with a significantly greater reduction in the rate of cardiovascular events and cardiovascular death compared with clopidogrel $(9.8 \%$ vs $11.7 \%$; $\mathrm{P}=.003)$. They also found that ticagrelor reduced the rate of all-cause mortality $(4.5 \%$ vs $5.9 \%$; $\mathrm{P}=0.03$ ). However, the rate of overall major bleeding or fatal/life threatening bleeding was similar with clopidogrel and ticagrelor. These results were consistent regardless of ACS type and management strategy ${ }^{26}$

Although the rate of serious adverse events did not differ significantly between the ticagrelor and clopidogrel groups, discontinuation of study treatment was more common among patients who received ticagrelor. This difference was primarily due to dyspnea, which is a known adverse effect of ticagrelor treatment. Other causes of the higher rate of discontinuation in the ticagrelor group were minor and minimal bleeding events ${ }^{26,27,28,29}$ 


\section{Conclusion:}

The combination of clopidogrel plus aspirin was not inferior to aspirin plus ticagrelor dual therapy in reducing the rate of myocardial infarction, stroke, or death from cardiovascular causes among patients with stable cardiovascular disease or multiple cardiovascular risk factors. Furthermore, the risk of moderate to severe bleeding was increased slightly in both the groups. Our findings do support the use of dual antiplatelet therapy across the broad population tested where single antiplatelet therapy are not giving maximum benefits. There was a potential benefit in symptomatic patients (those with established vascular disease); this finding requires further study involving large number of Indian patients. Data on mortality rates suggest that dual antiplatelet therapy should be used judiciously in patients without a history of established vascular disease.

\section{Acknowledgements}

We would like to thanks Dr. Khanam and whole medicine department for supporting in study

\section{Declarations}

Funding: None

Ethical approval: None

\section{References}

1. Misra A, Nigam P, Hills AP, et al. Consensus physical activity guidelines for Asian Indians. Diabetes Technol Ther 2012; 14:83-98.

2. Joseph Loscalzo. Approch to the patient with possible Cardiovascular disease. Disorders of cardiovascular system. Harrisons Principles of Internal Medicine. Mc Graw Hill Education, 20 ed;6(231);1649.

3. Prabhakaran D, Jeemon $P$, Roy $A$. Cardiovascular Diseases in India: Current Epidemiology and Future Directions. Circulation. 2016 Apr 19;133(16):1605-20.

4. Cardiovascular diseases (CVDs) Fact Sheet. WHO. Reviewed September 2016. Available at: http://www.who.int/mediacentre/ facts heets /fs317/en/. Accessed on Nov 28, 2017.
5. Hansson GK. Inflammation, atherosclerosis, and coronary artery disease. N Engl J Med. 2005; 352: 1685- 1895.

6. Davì G, Patrono C. Platelet activation and atherothrombosis. N Engl J Med. 2007; 357: 2482-2494.

7. Fuster V, Badimon L, Badimon JJ, et al. Mechanisms of disease - the pathogenesis of coronary-artery disease and the acute coronary syndromes. N Engl J Med 1992; 326:310-8.

8. Ruggeri ZM. Platelets in atherothrombosis. Nat Med 2002; 8:1227- 34

9. Lopez AD, Murray CC. The global burden of disease, 1990-2020. Nat Med 1998; 4:12413.

10. Bhatt DL, Steg PG, Ohman EM, et al. International prevalence, recognition, and treatment of cardiovascular risk factors in outpatients with atherothrombosis. JAMA 2006; 295:180-9.

11. Antithrombotic Trialists' (ATT) Collaboration. Aspirin in the primary and secondary prevention of vascular disease: collaborative meta-analysis of individual participant data from randomised trials. Lancet 2009; 373:1849-60.

12. Steinhubl SR, Berger PB, Mann JT, 3rd, Fry $E T$, DeLago A, Wilmer $C$, et al. Early and sustained dual oral antiplatelet therapy following percutaneous coronary intervention: A randomized controlled trial. JAMA 2002; 288: 2411-2420.

13. Yusuf S, F Zhao, SR Mehta, et al. Clopidogrel in unstable angina to prevent recurrent events trial investigators. Effects of clopidogrel in addition to aspirin in patients with acute coronary syndromes without ST segment elevation. N. Engl. J. Med. 2001; 345:494-502.

14. Chen ZM, Jiang LX, Chen YP, et al. Addition of clopidogrel to aspirin in 45,852 patients with acute myocardial infarction: randomised placebo-controlled trial. Lancet 2005; 366:1607-21.

15. Sabatine MS, Cannon CP, Gibson CM, et al. Addition of clopidogrel to aspirin and 
fibrinolytic therapy for myocardial infarction with ST-segment elevation. N Engl J Med 2005; 352:1179-89.

16. Kang HJ, Clare RM, Gao R, Held C, Himmelmann A, James SK, et al. Ticagrelor versus clopidogrel in Asian patients with acute coronary syndrome: A retrospective analysis from the Platelet Inhibition and Patient Outcomes (PLATO) Trial. Am Heart J. 2015 Jun; 169(6):899-905.e1

17. Zhao Q, Zhu Y, Xu Z, Cheng Z, Mei J, Chen X, et al. Effect of Ticagrelor Plus Aspirin, Ticagrelor Alone, or Aspirin Alone on Saphenous Vein Graft Patency 1 Year After Coronary Artery Bypass Grafting: A Randomized Clinical Trial. JAMA. 2018 Apr 24; 319(16):1677-1686.

18. BAYER. Aspirin comprehensive prescribing information. http://www.fda.gov/ohrms/ dockets /ac/03/briefing/4012B1_03_App d\% 201-Professional\%20Labeling.pdf. Accessed February 3, 2018.

19. Kotseva K, Wood D, De Backer G, De Bacquer D, Pyörälä K, Keil U. EUROASPIRE III a survey on the lifestyle, risk factors and use of cardioprotective drug therapies in coronary patients from 22 European countries. Eur J Cardiovasc Prev Rehabil 2009; 16: 121- 37.

20. Rossini R, Capodanno D, Lettieri C, Musumeci G, Nijaradze T, Romano $\mathrm{M}$, et al. Prevalence, predictors, and long-term prognosis of premature discontinuation of oral antiplatelet therapy after drug eluting stent implantation. Am J Cardiol 2011; 107: 186-94

21. Yasmina $A$, de Boer $A$, Deneer $V H$, Souverein $\mathrm{PC}$, Klungel $\mathrm{OH}$. Patterns of antiplatelet drug use after a first myocardial infarction d uring a 10-year period. Br J Clin Pharmacol. 2017 Mar;83(3):632- 641.

22. Ferreira-González I, Marsal JR, Ribera A, Permanyer-Miralda G, García-Del Blanco B,
Martí G, et al. Background, incidence, and predictors of antiplatelet therapy discontinuation during the first year after drug-eluting stent implantation. Circulation 2010; 122: 1017-25.

23. Tuppin $P$, Neumann A, Danchin $N$, de Peretti C, Weill A, Ricordeau P, et al. Evidence-based pharmacotherapy after myocardial infarction in France: adherence-associated factors and relationship with 30-month mortality and rehospitalization. Arch Cardiovasc Dis 2010; 103: 363-75.

24. Lenzi J, Rucci $P$, Castaldini I, Protonotari A, Di Pasquale G, Di Martino $M$, et al. Does age modify the relationship between adherence to secondary prevention medications and mortality after acute myocardial infarction? A nested case-control study. Eur J Clin Pharmacol 2015; 71: 243-50.

25. Johnston SC, Amarenco $P$, Albers GW, Denison H, Easton JD, Evans SR, Ticagrelor versus Aspirin in Acute Stroke or Transient Ischemic Attack. N Engl J Med. 2016 Jul 7;375(1):35- 43.

26. Wallentin L, Becker RC, Budaj A, et al. Ticagrelor versus clopidogrel in patients with acute coronary syndromes. N Engl J Med 2009; 361: 1045-57.

27. Becker RC, Bassand JP, Budaj A, et al. Bleeding complications with the P2Y12 receptor antagonists clopidogrel and ticagrelor in the PLATelet inhibition and patient Outcomes (PLATO) trial. Eur Heart J 2011;32: 2933-44.

28. Amarenco P, Lavallee PC, Labreuche J, et al. One-year risk of stroke after transient ischemic attack or minor stroke. N Engl J Med 2016; 374: 1533-42.

29. Bonaca MP, Bhatt DL, Cohen $M$, et al. Longterm use of ticagrelor in patients with prior myocardial infarction. N Engl J Med 2015; 372: 1791-800. 